\title{
Communio und Eucharistie. Ekklesiologische Parallelen bei Dumitru Stăniloae und Joseph Ratzinger
}

\author{
Constantin PRiHOANCă ${ }^{*}$
}

This article is a critical engagement with D. Stăniloae's and J. Ratzinger's ecclesiological thought as shaped by the description of church as the body of Christ and the Trinitarian roots of this ecclesiology. Starting from practical problems of prayer and living a Christian life, the authors argue that God's relationship to the Christian community has primacy over God's relationship to individual believers. When one conceives of the Christian community as being the body of Christ, one can uphold the elevated Christian ideal of Eucharist Communio without making it unattainable. The authors show that the being of the church is given to the Christian community not as a possession or property, but as a task to be fulfilled through the power of Christ and of the Holy Spirit. One can discover that in becoming the church, the Christian community is elevated to the Trinitarian life in communion. Communion ecclesiology has the potential to bridge the divide between the Orthodox and Catholic churches.

Keywords: ecclesiology, Trinity, Communio, liturgy, Eucharist, community, announcement, Stăniloae, Ratzinger

\section{Einführung}

Mitte der 80er Jahre wurde Communio zum zentralen Stichwort der ökumenischen Gespräche. Von Anfang an wurde der ekklesiologische Begriff der Communio in den Zusammenhang mit der umfassenden trinitarischen Communio gestellt. Erst durch diese Komplementarität lässt sich ein umfassendes Verständnis des Ursprungs, der Gestalt und der Bestimmung der Kirche gewinnen. Die vorliegende Studie analysiert die strukturellen Gemeinsamkeiten der ökumenischen Kirchenlehre zweier bedeutender Theologen, Dumitru Stăniloae und Joseph Ratzinger Die gemeinsame ontologische Verwurzelung der orthodoxen und römischkatholischen Gemeinden durch die eucharistische Liturgie in der Communio der Dreifaltigkeit sowie die Differenzen in der äußeren Gestaltung der Kirchenstruktur und die damit zusammenhängenden Divergenzen werden aufgezeigt. Es geht darum, den Dialog zwischen der orthodoxen und römischkatholischen Ekklesiologie in einen trinitarischen Rahmen zu stellen und zu fördern, da nur die eucharistische Ekklesiologie die Möglichkeit bietet,

* Constantin Prihoancă, Forscher am Ökumenischen Institut der Universität Heidelberg. Kontakt: Plankengasse 1, D-69117 Heidelberg; E-mail: constantin.prihoanca@gmail.com, prihoanca@oek.uni-heidelberg.de. 
die Kluft zwischen der orthodoxen und der römisch-katholischen Kirche zu überwinden.

\section{Kirche und Trinität: Trinitarische Grundlagen der Kirche bei Dumitru Stăniloae}

Aus dem zentralen Zeugnis der orthodoxen Liturgie hebt Stăniloae die Stellung der Christologie innerhalb der trinitarischen Doxologie hervor. Eine reine Christus-bezogene Liturgie ohne das trinitarische Lob ist als Ausdruck der Ekklesiologie für orthodoxes Verständnis undenkbar. Das monarchische Prinzip orthodoxer Trinitätslehre, welches den Grund für Einheit und Vielfalt innerhalb der Trinität bildet, spiegelt sich in der Liturgie wider. Stăniloae betont die ostkirchliche Begründung kirchlicher Existenz: „die trinitarischen Beziehungen [werden] als eine Grundlage für das Verhältnis der Trinität

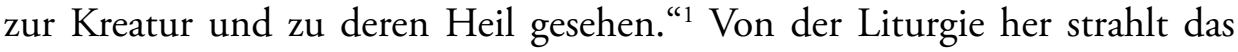
monarchische Prinzip - durch die Zusammenarbeit Christi mit dem Heiligen Geist - in die Wesensstrukturen und in die Aktivitäten der Kirche aus. ${ }^{2}$

Ursprung und Ziel der Kirche sind trinitarisch zu verstehen, sie folgen dem Ratschluss der Trinität. Die Kirche soll die Lebenseinheit der Trinität durch ihr Dasein zum Ausdruck bringen. ${ }^{3}$ Stăniloae schreibt, dass die Kirchenlehre notwendigerweise aus der orthodoxen Gotteslehre abgeleitet werden soll. Die Trinität bildet „die Wurzel und das Modell der Kirche, die ultimative Kirche. «Die absolute Kirche der Dreifaltigkeit» ist das normative Bild, die effiziente und letzte Causa der Menschenkirche, die Gemeinschaft wechselseitiger Liebe von oben und gibt das Modell und die innere Kraft der liebenden Gemeinschaft von unten. “4

\subsection{Die Dreifaltigkeit - Struktur vollkommener Liebe}

Stăniloae baut seine ganze Theologie auf der Trinitätslehre auf. Er nimmt die über die Dreifaltigkeit offenbarte Lehre der Hl. Schrift wahr und beschreibt die Notwendigkeit und den Vorrang einer apophatischen Erkenntnis dieses Dogmas. ${ }^{5}$ Darüber hinaus billigt Stăniloae eine enge und

${ }^{1}$ Dumitru Stăniloae, „Der Ausgang des Hl. Geistes vom Vater und seine Beziehung zum Sohn als Grundlage unserer Vergöttlichung und Kindschaft“, in: Lukas Vischer (Hg.), Geist Gottes - Geist Christi. Ökumenische Überlegungen zur Filioque-Kontroverse, Frankfurt am Main 1981, S. 153-164, hier 156.

2 D. Stăniloae, „Mişcarea ecumenică şi unitatea creştină în stadiul actual“, in: Ortodoxia 3-4/1963, S. 544-589, hier S. 550 f.

${ }^{3}$ D. Stăniloae, „Mişcarea ecumenică“, S. 551.

${ }^{4}$ Ibidem, S. 552 f.

${ }^{5}$ D. Stăniloae, Teologia Dogmatică Ortodoxă, Bd. I, Bucureşti 1996, S. 194. Ab hier weiterhin 
untrennbare Verbindung zwischen der rationalen und der apophatischen Erkenntnis Gottes (OD, Bd. I, S. 109 ff). Stăniloae stellt in seiner Dogmatik die Lehre über die Trinität mit dem ständigen Bezug auf die Grenzen menschlicher Rationalität und sprachlicher Begrifflichkeit dar, die kein adäquates Werkzeug für die Begründung des Trinitätsmysteriums bieten können (TDO, Bd. I, S. 195 f).

\subsubsection{Die Heilige Dreifaltigkeit - das Dogma}

Wie jede dogmatische Formulierung ist das Trinitätsdogma das Bekenntnis des Glaubens an eine Realität, die uns rettet, und enthält die minimale und notwendige Erkenntnis für die Erlösung. Trotz dieser offenbarten Erkenntnis des trinitarischen Dogmas bleibt die Existenzweise Gottes ein tiefes Geheimnis für die Menschen. ${ }^{6}$ Die Rolle dieses Dogmas „von der wesenseinen Gottheit in drei Personen“ (OD, Bd. I, S. 257) ist die Abgrenzung wahrer Gotteslehre von falschen oder wertlosen Lehren. Nach Stăniloae wird nur durch die Erkenntnis dieses Dogmas den Menschen die richtige Verbindung mit einer Gottheit ermöglicht, die den Grund für eine ewig liebende und ewig währende Gemeinschaft mit uns legt (TDO, Bd. I, S. $196 \mathrm{f})$.

Unter dem Einfluss der Hochscholastik greift Stăniloae in seiner Dogmatik die Gottesproblematik in zwei Schritten auf, wie W. Pannenberg klar gezeigt hat ${ }^{7}$ : Zuerst stellt er die Lehre von dem einen Gott dar, und in einer zweiten Phase wird von dem dreieinigen Gott gesprochen.

\subsubsection{Das Wesen Gottes}

Der von östlichen Kirchenvätern betonte Unterschied zwischen dem Wesen und den Werken Gottes ist von Stăniloae übernommen worden (OD, Bd. I, S. 137). Er betrachtet die Werke Gottes als Energien bzw. Eigenschaften Gottes, durch welche Gott sich selbst offenbart und kommuniziert (OD, Bd. I, S. 137 ff. u. 150 f). Diese dynamischen Manifestationen Gottes zeigen sich um das Wesen herum, sie sind Weise seiner Kommunikation, enthüllen aber nicht das Wesen Gottes selbst (OD, Bd. I, S. 139).

Von allen Attributen Gottes bewertet Stăniloae die „Existenz an sich“, welche von Dionisius Areopagitus mit dem Wesen Gottes gleichgesetzt

als TDO abgekürzt. Siehe auch: D. Stăniloae, Orthodoxe Dogmatik, Bd. I, Zürich-EinsiedelnKöln-Gütersloh 1985, S. 109-131. Ab hier weiterhin als OD abgekürzt.

${ }^{6}$ Ibidem.

${ }^{7}$ Wolfhart Pannenberg, Systematische Theologie, Bd. I, Göttingen 1988, S. 305. Anmerkung 72. 
worden ist und den Grund alles Seienden bildet, als das Wichtigste (OD, Bd. I, S. 141). Das Wesen kann nach Meinung von Stăniloae nur in einem Subjekt existieren (OD, Bd. I, S. 141 f, 147 f). Er erläutert in seiner Dogmatik, dass der Grund aller Eigenschaften Gottes, der Grund des Wesens selbst, die hypostatische Realität bzw. die dreifache göttlich-hypostatische Wirklichkeit ist (OD, Bd. I, S. 141). ${ }^{8}$ Das göttliche Wesen kann nie als Existenz gedacht werden, die seiner Hypostasierung im Vater und vom Vater her aus Ewigkeit im Sohn und im Hl. Geist voranginge. ${ }^{9}$ Es gibt einen aus der patristischen Literatur übernommenen Vorrang ${ }^{10}$ der trinitarischen Personen im Denken vom Stăniloae, in welchem das Fundament von Gottes Wesen und aller anderen Eigenschaften zu sehen ist:

„Die göttliche personale Wirklichkeit ist in eminenter Weise undeterminiert, da sie die Hypostasierung der Über-Existenz ist, durch die jedes geschaffene Wesen seine Existenz erhält. Es lässt sich sagen, Gott ist dreipersonale Über-Essenz oder über-essentielle DreiPersonalität. Was diese Über-Essenz ist, wissen wir nicht. Über sie lässt sich nur sagen, dass sie durch sich selbst das ist. Wie jede Essenz ist sie aber nur dadurch wirklich, dass sie in hypostatischer Weise in Personen vorhanden ist." (OD, Bd. I, S. 142)

Dadurch kommt das Merkmal von Stăniloaes Gotteslehre zum Ausdruck: Alles, was Gott zugeschrieben werden kann - einschließlich das Wesen Gottes - gehen auf die trinitarische Gemeinschaft zurück. Die Realität trinitarischer Personen ist absolut frei von jedem Referenzsystem und deswegen auch das letztgültige Fundament aller ihrer Manifestationen (OD, Bd. I, S. 144). Über diese personale Wirklichkeit Gottes lässt sich nichts sagen, sie ist apophatisch (OD, Bd. I, S. 146 ff). Sie übersteigt alle definierbaren Attribute. Alle durch Erkenntnis oder Erfahrung greifbaren Eigenschaften gehören zur Kategorie der Existenz während das dreipersonale Subjekt als überexistent zu verstehen ist (OD, Bd. I, S. 146).

Die Eigenschaften des überexistenten und rein geistigen ${ }^{11}$ Gotteswesens sind das ,in-sich-Sein“ (OD, Bd. I, S. $141 \mathrm{ff}$ ), die göttliche Unendlichkeit (OD, Bd. I, S. 150 ff), die absolute Einheit (OD, Bd. I, S. 154 ff), die

\footnotetext{
${ }^{8}$ Siehe: D. Stăniloae, Sfânta Treime sau La început a fost iubirea, Bukarest 1993, S. 26.

${ }^{9}$ Ibidem, S. 27 ff. u. 37 f.

${ }^{10}$ Dionisius Areopagitus, De divinis nominibus, P.G. 3, 818-820. Maximus der Confessor, Ambigua. P.G. 91, 1153.

${ }^{11}$ D. Stăniloae, Sfânta Treime, S. 10.
} 
Ewigkeit (OD, Bd. I, S. 159 ff), die Allgegenwart (OD, Bd. I, S. $182 \mathrm{ff})$ und die Allmacht (OD, Bd. I, S. 196 ff). Neben den Eigenschaften, die dem hypostasierten Wesen beigelegt werden, nennt Stăniloae folgende Attribute Gottes: die Allwissenheit (OD, Bd. I, S. 210 ff), die Weisheit (OD, Bd. I, S. $222 \mathrm{ff}$ ), die Heiligkeit (OD, Bd. I. S. $235 \mathrm{ff}$ ), die absolute Freiheit, ${ }^{12}$ die Güte (OD, Bd. I, S. 251 ff) und die Liebe (OD, Bd. I, S. 252 ff). Alle diese Eigenschaften quellen aus der Gemeinschaft der Dreifaltigkeit hervor, und der Grund dafür ist auf die Personen der Trinität zurückzuführen (OD, Bd. I, S. 160 f, S. 226, S. 242 f, S. 267 f). Kein personales Attribut kann einer unpersonalen Substanz zugeschrieben werden (OD, Bd. I, S. 160, S. 267).

\subsubsection{Der Personbegriff}

Gott wird als „überrationelles Paradox der vollkommenen Einheit der drei unterschiedlichen Personen" beschrieben (OD, Bd. I, S. 261). Eine Darstellung des trinitarischen Geheimnisses Gottes ist von Stăniloae auf Basis der Analogie zu den Menschen vorgenommen worden. So wie die Menschen dieselbe Wesenseinheit in einer mannigfachen Personenvielfalt besitzen, kann man dem einen Wesen Gottes drei Personen zuschreiben (OD, Bd. I, S. 262). Diese Analogie ist allerdings nicht sehr passend, weil dadurch Gott einer Kategorie zugeordnet wird. ${ }^{13}$

Stăniloae entwickelt den Personbegriff, indem er von Perichorese und Dynamik spricht (OD, Bd. I, S. 89). Er nimmt das Wesen nur in seinem konkreten Existenzmodus, in jeder Person der Trinität wahr. Auf diese Weise will er dem abendländischen Primat des Wesens über die Personen der Trinität die östliche Lehre entgegensetzen. ${ }^{14}$ In seiner Auffassung ist jede Person der Trinität Trägerin des göttlich-unwiederholbaren Wesens und somit in vollkommener Weise Gott, ohne von den anderen Personen getrennt zu sein und ohne sich mit den anderen zu vermischen. ${ }^{15}$ Weil die Relationen ein Subjekt und damit eine Handlungsquelle voraussetzen, lehnt er die thomistische Auffassung der göttlichen Personen als „subsistierende Relationen“ ab. ${ }^{16}$ Die Personen werden von Stăniloae als „Subjekt in Relation“

\footnotetext{
${ }^{12}$ Ibidem, S. 22.

${ }^{13}$ Siehe auch: W. Pannenberg, Systematische Theologie, S. 308.

${ }^{14}$ Marc-Antoine Costa de Beauregard, Osé comprendre que Je t'aime, Paris 1982, S. 22.

${ }^{15}$ D. Stăniloae, Sfânta Treime, S. 33; siehe auch: OD, Bd. I, S. 264.

16 Diese Beschreibung ist sorgfältig von der modernen katholischen Theologie bewahrt worden. Siehe auch: Joseph Ratzinger, Dogma und Verkündigung, Freiburg im Breisgau 1973, S. 210: „Personen sind Relationen, reines Bezogensein“; siehe auch: Karol Józef Wojtyla, Person and Community. Selected Essays, Berlin-New York 1993, S. 165-180.
} 
oder als Hypostase beschrieben. ${ }^{17}$

\subsubsection{Vollkommene Einheit unterschiedlicher Personen}

Jede Person der Dreifaltigkeit bringt, nach Stăniloaes Meinung, die vollkommene Einheit mit den anderen zwei Personen durch zwei Elemente zum Ausdruck: die Wesenseinheit und die vollkommene Liebe (OD, Bd. I, S. 246). Das heißt, dass in der Wirkung einer Person die anderen beiden Personen vollkommen anwesend und zusammen tätig sind (OD, Bd. I, S. 264). Die abendländische Missachtung dieser vollkommenen Einheit unterschiedlicher Personen und die Betonung der Wesenseinheit führte nach Meinung von Stăniloae dazu, dass die trinitarische Theologie in Westeuropa zu einer Form des Sabellianismus wurde, von dem das filioque ein konkreter Ausdruck ist. ${ }^{18}$

Alle drei Hypostasen sind in vollkommener Weise ineinander, sie besitzen gemeinsam die ganze göttliche Natur (OD, Bd. I, S. 258, S. 266) und im Bewusstsein jeder trinitarischen Person muss das Bewusstsein der beiden anderen Personen vollkommen durchsichtig sein (OD, Bd. I, S. 267). Stăniloae überträgt, seiner Tradition entsprechend, jede Eigenschaft, die in den Schuldogmatiken dem Wesen zugeschrieben wird, den trinitarischen Personen, mit der Begründung, dass es ein abstraktes Wesen nicht geben kann (OD, Bd. I, S. 268). Alle Attribute erscheinen in den trinitarischen Beziehungen, ohne dass es zu einer Verwechslung kommen kann. Vielmehr sind die gemeinsamen Eigenschaften der Dreifaltigkeit einzigartig von jeder Person durch ihre sie definierenden Attribute geprägt (OD, Bd. I, S. 268). Die persönlichen Eigenschaften beschreibt Stăniloae als „die überwesentliche Qualität des Vaters, des Sohnes und des Heiligen Geistes, die keinen Tausch untereinander und keine Vermischung miteinander zulassen" (OD, Bd. I, S. 258). Die nach Maßgabe unserer Vorstellungen gebrauchten Kategorien „Beziehung" und „Einheit" können nicht entsprechend auf die Trinität angewendet werden:

„Weder die Einheit darf zugunsten der Beziehung aufgehoben werden

${ }_{17}$ D. Stăniloae, Iisus Hristos sau restaurarea omului, Craiova 1993, S. 109 ff; siehe auch: D. Stăniloae, „Studii catolice recente despre filioque“, in: Studii Teologice 1973, S. 471-505, hier S. 487, S. 493: „Nicht die Person ist eine Eigenschaft der Relation, sondern umgekehrt. Die Personen sind nicht Relationen in einem Wesen, sondern Subjekte, Hypostasen welche das Wesen in sich tragen und verwirklichen."

18 Siehe: D. Stăniloae, „Studii catolice“, S. 477 ff; idem, „Ființa şi ipostasurile“, S. 57. Diese Position wird auch von anderen orthodoxen Theologen der Gegenwart vertreten; siehe: z. B. Johanes Zizioulas, „The doctrin of the Holy Trinity“, in: Christoph Schwöbel (Hg.), Trinitarian Theology Today, Edinburgh 1995, S. 44-60. 
noch die Beziehung zugunsten der Einheit. Die Heilige Dreieinigkeit ist indessen über die Unterscheidung von Einheit und Beziehung, so wie wir sie verstehen, erhaben. Die gegenseitige Bezugnahme ist eine Tätigkeit, und diese geschieht wesentlich in Gott, deutet aber zugleich auf eine Unterscheidung derer, die miteinander in Beziehung treten. Die Beziehung ist etwas für die göttlichen Personen Gemeinsames, obwohl jede Person innerhalb dieses gemeinsamen Aktes ihre eigene Stellung innehat.“ (OD, Bd. I, S. 269)

Die Existenz des göttlichen Wesens ist nichts anderes als das konkrete Dasein göttlicher Subjektivität ${ }^{19}$ auf dreierlei Weise, wobei diese drei sich wechselseitig erschließen (OD, Bd. I, S. 272). Stăniloae unterstreicht die reine und aktive Subjektivität göttlicher Personen, deren Innerlichkeit nichts Objekthaftes dulden kann. Die trinitarische Gemeinschaft ist für ihn unendlich und fortwährend, so dass es zwischen den Personen der Dreifaltigkeit keine Diskontinuität und kein subsistierendes „Objekt“ gibt. ${ }^{20}$ Die vollkommene Communio zwischen den Personen erlaubt keine gegenseitige Behandlung als Objekt. Die Kontinuität zwischen dem Wesen und den Personen ist vollkommen. Auch die Verschiedenheit der Hypostasen unterbricht die

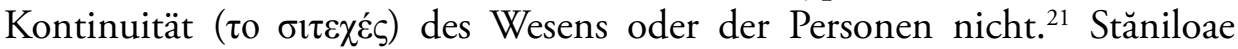
begründet diese Kontinuität mit dem geistlichen Charakter göttlicher Natur (OD, Bd. I, S. 208f, S. 266). Die göttlichen Hypostasen, die füreinander ganz offen und durchlässig existieren, durchdringen einander in vollkommener Liebe und sind in vollkommener, kontinuierlicher Weise ineinander, weil sie zusammen das göttliche Wesen besitzen (OD, Bd. I, S. 266).

Gott ist als reines Subjekt oder als Trinität reiner Subjekte oder Personen zu betrachten ${ }^{22}$ (vgl. OD, Bd. I, S. 272 f). Gott ist Eins aufgrund der Wesenseinheit und zugleich Dreiheit, weil die reale Liebe nur zwischen real verschiedenen Subjekten entsteht und besteht (OD, Bd. I, S. 266). Weil Gott immer Liebe war und ist, hat er auch andauernd einen personalen und trinitarischen Charakter:

„Das höchste bestehende geistige Wesen ist also nicht ein bewusstes Einzelsubjekt, sondern eine Gemeinschaft von Subjekten, die

\footnotetext{
19 Stăniloae benutzt den Begriff Subjektivität nicht in seinem normalen Bedeutungsgehalt als vom Subjekt gegebenen illusorischen Inhalt, sondern als absolut freie Existenzart Gottes: „durch Sich-Selbst-Sein“ und „durch Sich-Selbst-zu-entscheiden“, siehe: OD, Bd. I, S. 280 f.

${ }^{20}$ D. Stăniloae, Sfânta Treime, S. 29 f.

${ }^{21}$ Ibidem, S. 30, siehe auch: P.G. 32, S. 332-333, P.G. 26, S. 723.

${ }^{22}$ D. Stăniloae, Sfânta Treime, S. 22.
} 
füreinander vollkommen transparent, durchschaubar sind. Die Dreiheit der göttlichen Personen gehört zum göttlichen Wesen schlechthin hinzu, ohne dass die drei Personen sich dadurch in der Einheit dieses Wesen vermischen." (OD, Bd. I, S. 267)

Stăniloae vermischt die Hypostasen miteinander nicht, weil eine Vermischung zur Auflösung der Liebe führt, und er akzeptiert auch keine Spaltung des Wesens, die zu einer Verarmung der Hypostasen führen könnte.

Stăniloae erkennt die Existenz Gottes auf Basis der Offenbarung, aber er betont, apophatisch, die Unfähigkeit unseres Erkenntnisvermögens zu wissen, ${ }^{23}$ "was“ Gott ist. Es gelingt ihm nur zu sagen, dass Gott Liebe ist, und somit „Leben an sich“ und „Licht an sich“, ausgehend von seiner ultimativen, unvermischten und dreipersonellen Communio-Einheit des Wesens und der Liebe. $^{24}$

\subsection{Die Liturgie als Erscheinungsort der Communio zwischen Trinität und} Kirche

Die Rettung der Menschen und deren Vergöttlichung als Werk der Aufnahme in die Communio der Dreifaltigkeit wird von Stăniloae als Erweiterung der liebevollen innertrinitarischen Beziehungen zu den mit Bewusstsein begabten Geschöpfen angesehen (TDO, Bd. I, S. 197). Durch den menschgewordenen Gottessohn treten die Menschen als Kinder in die Communio mit dem Vater hinein, und durch den Hl. Geist beten wir zum Vater oder sprechen mit Ihm als seine Söhne (TDO, Bd. I, S. 198). ${ }^{25}$ Die Schöpfung benötigt ein von der Trinität unterstütztes und begleitetes Bestreben, aus Freiheit, zum Eintritt in die Communio mit der Dreifaltigkeit. ${ }^{26}$

\subsubsection{Die Liturgie - Doxologie des kommenden Trinitätsreiches und der Hl. Dreifaltigkeit}

Das Lob des Gottesreiches kann als immer anwesendes Lob in allen orthodoxen liturgischen Handlungen vom einfachsten „Vater unser“ und vom Herzensgebet ${ }^{27}$ bis zur Liturgie angesehen werden. Den Kern dieses Lobes findet Stăniloae in der großen Segnung, welche am Anfang jedes Sakramentes gesprochen wird: „Gesegnet sei das Reich des Vaters und des Sohnes und

\footnotetext{
${ }^{23}$ Ibidem, S. 18.

${ }^{24}$ Ibidem, S. 23 f, S. 30.

${ }^{25}$ Siehe: Gregor von Nazianz, Oratio XXXI, P.G. 94, S. 145 C.

${ }^{26}$ D. Stăniloae, Sfânta Treime, S. 16.

${ }^{27}$ Das Herzgebet, das auch unter dem Namen Jesusgebet bekannt ist, stellt den Kernpunkt aller orthodoxen Partikulargebete dar und ist überall als ein Merkmal des Hesychasmus anerkannt worden.
} 
des Heiligen Geistes jetzt und immerdar und von Ewigkeit zu Ewigkeit. Amen." ${ }^{28}$ Die Segnung der Gemeinde ist mit der Gewissheit verbunden, am kommenden Reich Anteil zu haben. Die Gemeinde selbst weiß aus der bisherigen Teilnahme an der Liturgie und aus dem Zeugnis der Hl. Schrift (Eph. 1,3), dass alle, die das Gottesreich segnen, dadurch selbst von Gott gesegnet werden (SC, S. 133).

Die ganze Verehrung konzentriert sich auf den dreieinigen Gott. Die Verherrlichung Gottes soll einer apophatischen Ergänzung der großen, uns aus der Offenbarungsgeschichte bekannten Taten Gottes dienen. Da durch die rationale Erkenntnis keine ausreichenden Aussagen über Gott gemacht werden können, bevorzugt Stăniloae den Lobgesang, der es den menschlichen Stimmen möglich macht, die Unaussprechlichkeit Gottes durch Lobpreisung zum Ausdruck zu bringen. ${ }^{29}$ Dadurch kommt das Lob des versammelten Gottesvolkes zur immerwährenden Lobpreisung der Engel hinzu. ${ }^{30}$ Es wäre aber falsch, diesen Lobpreis nur als liturgisches oder sogar individuelles Gebet zu bezeichnen: Das ganze Leben eines Christen, sein ganzes Denken, sein Wille und alle seine Gefühle müssen ein lebendiger Lobpreis Gottes sein. Die liturgische Form des Gebets ist nur die äußere Darstellung und Bekundung der inneren Haltung des Menschen vor Gott.

\subsubsection{Die Liturgie - Ort der Verkündigung Christi}

Für diejenigen, die mit der orthodoxen Liturgie vertraut sind, stellt dieser Anfangsteil der Liturgie nur eine geschichtliche Reminiszenz dar und ist gleichzeitig ein Beweis der ernsthaften Verantwortung christlicher Gemeinden in der Auseinandersetzung mit der religiös kosmopolitischen Gesellschaft der antiken Welt. Die heutige Situation orthodoxer Gemeinden berücksichtigend, in welchen die Anzahl kühler, verfremdeter und unwissender Christen gestiegen ist, schlägt Stăniloae eine katechetische Betonung dieses Teiles und sogar eine Erweiterung vor (SC, S. 132). Er beruft sich auf die ersten rumänischen Übersetzer der Liturgie von Johannes Chrysostomos als Begründung dafür, dass alle Christen immer vor diesem Ruf stehen und dazu verpflichtet sind, dem, „der euch beruft“ (Gal. 5,8), Antwort zu geben (SC, S. $132 \mathrm{f})$.

${ }^{28}$ D. Stăniloae, Spiritualitate și comuniune în Liturghia Ortodoxă, Craiova 1986, S. 133. Ab hier als SC abgekürzt.

${ }^{29}$ Siehe: Paulus Zacharias, „Einführung in die Orthodoxe Liturgie“, in: Ernst Benz \& Lev A. Zander, Evangelisches und orthodoxes Christentum in Begegnung und Auseinandersetzung, Hamburg 1952, S. 78-100, hier S. 92.

${ }^{30}$ Ibidem. 
Diese Vorbereitung bildet die Voraussetzung für das Verständnis der neutestamentlichen Lesungen. Nur die von allen Sünden und fremden Gedanken gereinigten und geheiligten Seelen der Menschen können die Lehre Jesu Christi verstehen und durch sie ein reineres Leben führen (SC, S. 191). Die aus den Apostelbriefen und aus der Apostelgeschichte vorgetragenen Lesungen sind keinesfalls als theoretische Betrachtung, sondern als eine doxologische Darstellung der Heilstaten Gottes und als Vergegenwärtigung des Logos durch Verkündigung des Evangeliums anzusehen (SC, S. 191, S. 196). ${ }^{31}$ Jede Perikopenlesung spiegelt in konzentrierter Form die ganze Aktivität Christi wider und wird gleichzeitig zu einer Gelegenheit für die Kirche, ihren Dank darzubringen (SC, S. 191, S. 194). Die Ordnung der Lesungen, d. h. zuerst aus der Apostelgeschichte oder aus den Apostelbriefen und danach aus einem der vier Evangelien, weist in der Theologie Stăniloaes auf die notwendige Folge für das richtige Verständnis Christi und seiner heilenden Taten hin. Auf der Basis der Apostel steht die Lehre der Kirche. Die ununterbrochene und dauerhafte Apostolizität der Kirche ist die Fortsetzung des von den Aposteln übernommenen, wahren und vollständigen Verständnisses Christi, durch die institutionell sichtbaren Strukturen der Kirche (SC, S. 192). Das Kriterium und die letztgültige Autorität dieser Lehre ist Christus selbst (ibidem). Stăniloae betont die Verbindung zwischen dem alten und dem neuen Bund und die Erfüllung der Verheißungen Gottes an das Volk Israel für alle Menschen, die seine Offenbarung in Christus angenommen haben (SC, S. 194). Gleichzeitig mit der ersten Lesung betet der Priester leise für die ganze Gemeinde, die gerade das offenbarte Wort Gottes hört. In seinem Gebet erbittet der Priester für die Gläubigen und für sich selbst „das reine Licht der Gottheit“, das in die Herzen ausstrahlen und „die Augen der Vernunft" für das richtige Verständnis evangelischer Verkündigung erleuchten soll. Bemerkenswert ist der Akzent, den Stăniloae, in Nachfolge von Gregor Palamas und Symeon dem Neuen Theologen, auf die apophatische Gottesoffenbarung als Licht legt. Diese Sicht bevorzugt nicht eine rationale, natürliche und durch Studium erworbene Erkenntnis Gottes, sondern es geht um die spirituelle Erkenntnis Gottes, die aus dem strahlenden Licht Christi entspringt (SC, S. 195 f). Die Ursache dieser Stellungnahme Stăniloaes besteht darin, dass einerseits Gott ohne seine freie Offenbarung nicht erkannt werden kann (ibidem) und anderseits die menschliche Vernunft allein zu einer richtigen Erkenntnis Gottes unfähig ist (OD, Bd. I, S. 256 f). Eine neue Ebene wird von der gesamten Gemeinde als Kirche erreicht: Zuerst wird Gott um seiner Heiligkeit und seiner Hilfe

${ }^{31}$ Siehe: P. Zacharias, „Einführung“, S. 90 f. 
willen angerufen und gelobt, und dann möchte die Gemeinde der durch Licht vermittelten Erkenntnis Gottes teilhaftig werden (SC, S. 196).

Unmittelbar darauf folgt die Lesung aus dem Evangelium. Aus jeder dieser Lesungen kann man Christus und sein ganzes Heilswerk kennenlernen. Die Lesungen eines ganzen kirchlichen Jahres bieten eine gesamte Darstellung der Heilstaten Gottes durch Jesus Christus (SC, S. 198). Stăniloae betont, dass eine anfragende, kritische und kalte Lesung des Evangeliums typisch protestantisch sei, ${ }^{32}$ und die Orthodoxen das Evangelium als Gelegenheit des doxologischen Lobpreises Gottes verstehen sollen (SC, S. 198 f). Über die heilenden Taten Christi können in der Kirche auch die Laien reden, so dass in der orthodoxen Tradition die ersten Lesungen überwiegend von nicht ordinierten Christen gehalten worden sind (SC, S. 199). Die Verkündigung des Evangeliums bleibt aber exklusiv die Aufgabe des Klerus. Diese kategorische Trennung, die in der orthodoxen Gottesdienstordnung vorgesehen ist, wird von Stăniloae durch die spezielle Sendung des Sohnes in die Welt begründet. So wie Christus einen besonderen Auftrag für die Rettung der Menschheit vom Vater bekam, so haben die ordinierten Priester die Fortsetzung des Auftrags Christi übernommen und geben an seiner Stelle die Lehre des Evangeliums an die Gemeinden weiter (SC, S. 199).

Nach jeder Lesung wird Gott von seinem Volk mit dem „Halleluja!“ und „Ehre sei dir Gott, ehre sei Dir!“ gelobt. Die Verkündigung heilender Taten Gottes wird ständig Anlass eines doxologischen Lobpreises Gottes. Eine Segnung der Gemeinde mit der Auferstehungsikone des Evangeliums beschließt den katechetischen Teil der Liturgie durch die feierliche Verkündigung des aktuell kommenden Reiches Gottes und öffnet den Eintritt in die Liturgie der Gläubigen (SC, S. 199).

\subsubsection{Die Liturgie der Gläubigen - Opfer-und Abendmahlsliturgie}

Das Ende des katechetischen Teils der Liturgie sollte als Zeichen des eschatologischen Gerichtes Gottes eine weitere Trennung zwischen den

\footnotetext{
${ }^{32}$ Diese Einstellung von Stăniloae ist leider nicht konsequent nachvollziehbar. Er lehnt die historischen oder exegetisch-kritischen Methoden Tübinger und Göttinger Theologieschulen grundsätzlich $a b$, versucht aber immer wieder die Argumentation dieser Methoden für die Unterstützung seiner Positionen einzusetzen. Als Beispiel der Verwendung dieser Methoden von Stăniloae ist die Auslegung der Schriftstelle Lk. 11,2: „dein Reich komme“. Diese Stelle wird nicht nur in Bezug auf die Heilige Schrift erörtert, sondern auch von einem „Kommentar zum Vater unser“ des Gregorius von Nyssa ausgehend. Gregor sagt, dass im Lukasevangelium nicht um die Ankunft des Reiches Gottes gebetet wird, sondern um die Ankunft des Geistes: „[...] dein Heiliger Geist komme, und errette uns[...]“. Stăniloae begründet die Position Gregors mit den zahlreichen Versionen der Zeitdokumente, die ihm zur Verfügung gestanden haben (siehe SC, S. 136).
} 
Teilnehmern am Gottesdienst bedeuten: Die in Christus erfüllte Zeit dieser Welt ist beendet, und die für die Communio-Feier in der Kirche verbliebenen Menschen sollen der Anwesenheit Gottes über den Jüngsten Tag hinaus gewiss sein (SC, S. 225). Die zur Abendmahlsfeier verbliebenen Gemeindeglieder dürfen die anderen und sich selbst nicht mehr als einzelne egoistische Personen betrachten. Sie stellen eine lebendige Einheit dar, in welcher alle für alle verantwortlich sein müssen (SC, S. 231). Die Gewissheit der gegenseitigen Zuständigkeit bildet in jedem Mitglied der christlichen Kirche ein konkretvernünftiges Gewissen kirchlicher Sobornizität (SC, S. 231, S. 248).

Das eschatologisch ausgerichtete Glaubensbekenntnis der Kirche als Beweis kirchlicher Katholizität wird von allen Gläubigen als Ausdruck der lebendigen Gotteserkenntnis gesprochen (SC, S. 248). Kein theoretisches Interesse bewegt die Christen zur Erforschung ihrer Glaubensinhalte, allein der Wille einer wirklichen Beziehung mit Gott bringt die Gemeinde zum Bekenntnis eines Gottes der Liebe (SC, S. 244).

\subsubsection{Die liturgische Anamnese}

Die liturgische Anamnese wird bei Stăniloae zuerst in ihrer apophatischen Dimension bewertet. Stăniloae glaubt, dass die Orthodoxie eine lebendige Verbindung zu Gott bevorzugt, weil sie in deren Entfaltung nicht nur die Vernunft, sondern auch die persönliche und gemeinschaftliche Erfahrung einsetzt. Der Inhalt dieser lebendigen Beziehung wird den einfachen Christen durch die ganze liturgische Anamnese übermittelt (SC, S. 263). Die ersten Teile der Anamnese bringen die ganze Gemeinde zu einem Dialog mit Gott. Die Gemeinde eröffnet den Dialog, erinnert und bedankt sich für die vergangenen, bekannten oder unbekannten Taten Gottes, welche für das Heil und für das alltägliche irdische Wohlergehen der Menschheit getan worden sind (SC, S. 261, S. 270). Das Volk lobt Gott mit den Worten von Jesaja 6 „Heilig, heilig, heilig der Herr Zebaoth!", und mit der sichtbaren Gemeinde wird die ganze unsichtbare Kirche in den doxologischen Lobpreis Gottes einbezogen. Die anwesende Gemeinde erzählt nicht von der Herrlichkeit Gottes wie die Engel in Jesaja 6,3, sondern sie wendet sich an den dreieinigen Gott: „...von deiner Herrlichkeit ist die ganze Erde erfüllt.“

Die Darbringung der eucharistischen Gaben in der Anaphora betont das Priestersein aller Gläubigen in ihrer Verantwortung für die Schöpfung. Diese Darbringung ist für Stăniloae der liturgische Höhepunkt der Darbringung persönlich-christlichen Lebens an Gott. Dabei gehen weder das Leben noch die eucharistischen Gaben verloren, sondern kommen in einem ontologischverbesserten Zustand, als Garantie des ewigen Lebens, verwandelt durch die Wirkung des Heiligen Geistes, zurück (SC, S. 281 f). 
Die Liturgie als fortwährende Steigerung in der Communio mit der Dreifaltigkeit hat ihre Wurzeln in der ontologischen und durch den Heiligen Geist vollzogenen Umwandlung des Brotes und des Weines am Stiftungstag des Herrenmahls (SC, S. 269f). Wie damals so auch heute, werden die Elemente der Eucharistie in ihrem Wesen in den wahren Leib und in das wahre Blut Christi umgewandelt. Die Wandlung der Gaben findet „mit der Zustimmung des Vaters durch den Sohn und durch den Heiligen Geist" statt (SC, S. 293).

\subsubsection{Die Communio}

Das versammelte Volk Gottes, welches vom Heiligen Geist mit seinen Gaben beschenkt wurde, tritt in die persönlich-unmittelbare Communio mit dem durch seinen Leib und sein Blut anwesenden Christus hinein. Stăniloae hebt die Bewahrung des persönlichen Charakters jedes einzelnen Christen hervor. Die gegenseitige Teilhabe durch die Communio und in der Communio bringt keine Verschmelzung der Personen oder eine Auflösung des Menschlichen ins Göttliche mit sich, vielmehr bewahrt die Communio die Einzigartigkeit jeder Person. Durch das ganze Geschehen entsteht kein individueller Beziehungsakt zwischen Gott und jeder Einzelseele. ${ }^{33}$ Bei der Darreichung der Eucharistie bleibt ein klarer Unterschied zwischen den Ordinierten und dem einfachen Volk Gottes: Auch wenn beide vom gleichem Kelch die Eucharistie bekommen, bleibt die ontologische Differenz zwischen den beiden Ständen erhalten. Von den vier Teilen des Agnus Dei bekommen die Kleriker die Partikel HS (= Christus) und die Laien die Partikel NI und KA. Die Kommunion ist für jeden Christen eine direkte Beziehung zum Erlöser und in diese Beziehung tritt jeder durch persönlichen Ruf hinein (SC, S. 336). Der Hauptzweck der Kommunion wird zur Vergewisserung für jede Person hervorgehoben: „Der Knecht Gottes wird zur Vergebung der Sünden und für das Leben der kommenden Welt dargereicht" (SC, S. 341). Die Argumentation Stăniloaes für das ewige Leben wird nicht nur durch die ostkirchliche Patristik gestützt, sondern auch durch die kritische Stellungnahme Joseph Ratzingers zur wissenschaftlichen Trennung zwischen Biologie und Theologie. Das Wesen des Menschen kann nicht allein vom Standpunkt der Biologie aus erschlossen werden. Das wäre im Gegensatz zu den Glaubenssätzen, welche von der Spiritualität des Biologischen, von der Körperhaftigkeit des Spirituellen und von der Menschwerdung Gottes sprechen (SC, S. 346). ${ }^{34}$ Der Mensch gewinnt gerade durch den Akt

\footnotetext{
${ }^{33}$ Siehe: P. Zacharias, „Einführung“, S. 98.

${ }^{34}$ Siehe: J. Ratzinger, Die Tochter Sion, Einsiedeln 1977, S. 51.
} 
vollkommener Liebe zwischen Gott und Mensch, durch die Kommunion, die Möglichkeit der wertvollen und ewigen Existenz in der Einigung mit Gott und in der Verantwortung Ihm gegenüber (SC, S. 354). Christus hat durch das Kreuz den Tod besiegt und die Kommunion bietet allen Christen heute die Gewissheit der Auferstehung und des kommenden Lebens (SC, S. 361).

\subsection{Die Liturgie nach der Liturgie}

Der universale Auftrag der Kirche soll von ihren Mitgliedern in der Welt fortgesetzt und erfüllt werden. Die Kirche als Haus Gottes soll in die Welt ausstrahlen. Stăniloae hebt neben dem persönlichen Charakter der Begegnung Gott-Mensch in der Liturgie auch ihren kosmischen Charakter hervor. Er sieht in der Liturgie die vollkommene Vollendung jenes Einbruchs göttlicher Herrlichkeit in diese Welt. Durch die Rückkehr der Christen in die Welt soll auch die Schöpfung die Garantie der Verklärung und der Auferstehung Christi empfangen. Stăniloae begründet seine Überzeugung, dass das Weltall am Ostergeheimnis Anteil hat, durch den speziell auserwählten Ort der Auferstehungsverkündigung, nämlich außerhalb der Kirchengebäude unter freiem Himmel.

\subsection{Zusammenfassung}

Die Gemeinschaft der Kirche nährt sich geistlich aus der Communio der Dreifaltigkeit und wird durch die Zusammenwirkung der Trinität in die ewige Communio geführt. ${ }^{35}$ Stăniloaes Darstellung führt zu einer Verwischung der Grenze zwischen der Kirche als geistlicher Gemeinschaft und der Kirche als Institution mit ihrer hierarchischen Struktur. Durch diese Verwischung unterstützt Stăniloae den Kircheninstitutionalismus. Daraus folgt, dass die Hierarchie eine soteriologische Funktion zur Vermittlung des Heiligen Geistes an die Gläubigen hat. ${ }^{36}$ Diese Vorstellung unterstützt eine monarchische Ekklesiologie $^{37}$ und reflektiert Stăniloaes Dreifaltigkeitslehre, sie birgt allerdings die Gefahr der Unterordnung aller Laien und die Möglichkeit des Missbrauchs der Gnade zur eigenen Machtentfaltung. ${ }^{38}$

\section{Kurze Einführung in der Trinitätslehre von Joseph Ratzinger}

\footnotetext{
35 D. Stăniloae, „Die Universalität und die Ethnizität der Kirche in der orthodoxen Auffassung", in: Referate des Theologischen Südosteuropa-Seminars, Universität Heidelberg, 6-17 September 1976, S. 1- 17, hier S. 8.

${ }^{36}$ Siehe: OD, Bd. II, S. 226.

${ }^{37}$ D. Stăniloae, „Autoritatea Bisericii“, in: Studii Teolgice 3-4/1964, S. 183-215, hier S. 189200.

${ }^{38}$ Daniel Munteanu, Der tröstende Geist der Liebe, Neukirchen-Vluyn 2003, S. 242-247.
} 
Über die Trinität hat Ratzinger sehr wenig geschrieben, und wenn er das gemacht hat, dann immer mit dem Hinweis auf die Beziehung zwischen dem dreieinigen Gott und der Kirche. Dies deutet nur an, was sich beim genaueren Hinsehen bestätigt: Alles Entscheidende in seiner Ekklesiologie wurzelt in der Trinitätslehre. Das ganze Leben der Kirche - die Strukturen und die eucharistische Messe - ist entsprechend einer bestimmten Auffassung der Trinität entwickelt worden.

\subsubsection{Person in der Trinität}

Person in der Trinität besteht in reiner Relationalität - persona est relatio, sagt Ratzinger. ${ }^{39}$ So ist der Vater als Person die "Tat des Zeugens“ und nicht einfach der Zeugende. Ähnlich geht auch der Sohn „wirklich ganz daraufhin auf, Gesandter zu sein“41, er ist die Tätigkeit des Gesandtseins. Ratzinger sucht eine Bestätigung dieser Sicht des trinitarischen Seins als Person im Christuszeugnis des Neuen Testaments. Nach seiner Interpretation von Phil 2, 5-11 ist Jesus eine Person, die sich „ausgeleert“ hat, und „das Seinfür-sich aufgebend, in die reine Bewegung des Für eingetreten " ist. ${ }^{42}$ Diese Entäußerung ist „reine Bewegung“, das „Ganz-Aufgehen“ im Gesandtsein. Sie geschieht nicht an der Person Christi, sondern das Personsein Christi besteht in der Entäußerung. Um zu dieser Auffassung des Personseins zu gelangen, muss Ratzinger freilich der Tätigkeit des Sich-Entäußerns das Subjekt entziehen und dann diese Aktivität selbst zu einer Person festigen. Ratzinger scheut nicht, klar auszusagen: Es gibt kein hinter den Aktivitäten, Taten und Handlungen der göttlichen Personen verbliebenes „Ich“, die Handlungen dieser Personen sind ihr "Ich“. ${ }^{43} \mathrm{Zu}$ Recht kann man unterstreichen, dass sich die Vorstellung von Person als Beziehung einem klaren Verständnis entzieht. Abgesehen davon, dass Ratzinger die biblische Geschichte des Sohnes radikal umdeuten muss - der Sohn entäußert sich nicht, sondern ist die Aktivität der Entäußerungen - hat er Schwierigkeiten, das Sein Christi als reine Beziehung klar darzustellen. Das deutet sich schon darin an, dass manche Formulierungen inkonsistent und inkonsequent sind. Neben der Rede von der totalen Relativität findet man auch Aussagen wie: „Wenn es nichts gibt, worin er [der Sohn] bloßEr ist, keinerlei abgegrenztes Privatum, dann fällt er

39 Siehe J. Ratzinger, Einführung in das Christentum. Vorlesungen über das Apostolische Glaubensbekenntnis, München 2000, S. 112.

${ }^{40}$ J. Ratzinger, Einführung, S. 144; idem, Dogma, S. 221.

${ }^{41}$ Idem, Einführung, S. 149.

42 Ibidem, S. 178.

${ }^{43}$ Ibidem, S. 162. 
mit Jenem [dem Vater] zusammen, ist eins mit ihm. " ${ }^{44}$ Ratzingers Folgerung ist nicht schlüssig. Dass es nichts gibt, worin der Sohn bloß er ist, bedeutet, dass der Sohn in allem auch durch den Vater bestimmt ist, und das wiederum bedeutet, dass der Sohn in allem auch durch sich selbst bestimmt ist. Wenn es so wäre, dann ist der Sohn auch keine reine Relation, sondern wird in jedem Aspekt seiner Existenz durch die Beziehung zu seinem Vater bestimmt. Außerdem passt diese Beschreibung der trinitarischen Personen als reine Relationen nicht zu der von Ratzinger angenommenen biblischen Grundlage des trinitarischen Personseins im „Phänomen des Gottes, der im Dialog ist“ ${ }^{45}$ - es sei denn, man sucht hinter dem göttlichen Dialog nach etwas Tieferem und Eigentlichem. Reine Relationen können weder sprechen noch hören.

\subsubsection{Einheit in Trinität}

Aus der Auffassung des Personseins als reine Relation ergibt sich eine bestimmte Sicht trinitarischer Einheit. Weil jede Person eine totale Relativität ist, kann ihre Einheit nicht über ihr spezifisches personales „Ich-Sein“ verlaufen. Die trinitarische Einheit ist deswegen auch nicht eine differenzierte Einheit der in Relation stehenden Personen, sondern eine Einheit, in welcher der Vater, der Sohn und der Heilige Geist „zusammenfallen“ und so „reine Einheit“ sind. ${ }^{46}$ So stellt die Darstellung Ratzingers zusammen mit der ganzen westlichen Überlieferung eine einzige Linie dar: die Einheit der Trinität steht nicht auf der Ebene der Personen, sondern auf der Ebene des Wesens. Damit gewinnt aber das eine Wesen die Oberhand über die Relationen. Zwar behauptet Ratzinger, dass die Relationen „eine gleichermaßen ursprüngliche Form des Seins" wie das Wesen Gottes darstellen. ${ }^{47}$ Die Auffassung von der Gleichursprünglichkeit „des Elements des Einen“ und „des der Dreiheit“ würde auf eine Reziprozität in der Beziehung zwischen den beiden hindeuten. Ratzinger behauptet aber ausdrücklich, dass es die Gleichursprünglichkeit von Wesen und Personen der Trinität nur unter der Voraussetzung „einer umgreifenden Dominanz der Einheit" des Wesens geben kann. Ratzingers Auffassung des trinitarischen Personseins prägt seine anthropologische Konzeption: Die Unendlichkeit Gottes bestimmt die Existenz des Menschen, "der Durst nach dem Unendlichen gehört nun einmal zum Wesen des Menschen, ja, ist geradezu sein Wesen. Seine Grenze kann nur das Grenzlose

\footnotetext{
${ }^{44}$ Ibidem, S. 146.

45 J. Ratzinger, Dogma, S. 210.

${ }^{46}$ Idem, Einführung, S. 147.

${ }^{47}$ Ibidem, S. 143.
} 
sein. $[\ldots]^{\text {“ } 48}$

\subsection{Glaube als Grundstruktur menschlicher Beziehungen}

Durch die Generalisierung der menschlichen Handlungen gelingt Ratzinger eine Beobachtung, die er als Grundhaltung menschlicher Existenz ansieht: Glaube als verlässlichen Akt menschlichen Zusammenlebens, der sich in allen Aspekten alltäglichen Lebens mit oder ohne unsere Akzeptanz zeigt. ${ }^{49}$ Der Alltagsglauben ermöglicht, größtenteils unbewusst, jedem eine "gemeinsame Teilhabe am Verstehen und am Bewältigen der Welt". ${ }^{0}$ Das Grundprinzip für den Alltagsglauben liegt im persönlichen Vertrauen.

\subsubsection{Glaube als Eintritt in die kirchliche Gemeinschaft}

Das Menschsein ist in der Theologie Ratzingers im trinitarischen Abbild ein Ich, das immer ein Du benötigt. Der in der Tiefe des Ichs verankerte Glaubensakt ist ein „zutiefst persönlicher Akt“, ${ }^{51}$ der in sich gleichzeitig das „Mitsein“, die Anbindung an die anderen und die Erlösung aus der Isolierungskrankheit trägt. ${ }^{52}$ In der ständigen Werdung zum christlichen Menschen sieht Ratzinger eineAuflösung der eigenen Subjektivität und dieneue Geburt in dem größeren Ich der Kirche. In diesem Prozess wird der Einzelne in eine Communio- und Kommunikationsgemeinschaft mit der ganzen Kirche und nicht nur mit Jesus hineingeführt. Diese gleichzeitige horizontale und vertikale Verankerung - wobei die horizontale Dimension unbedingt aus der vertikalen zu verstehen ist - wird von Ratzinger als Verankerung in einer vorgegebenen Glaubens- und Gemeinschaftsstruktur gesehen. ${ }^{53}$ Deswegen kann er sagen, dass der christliche Glaube notwendigerweise der Glaube der Kirche ist. ${ }^{54}$ Dadurch vereinigen die Christen alle Erfahrungen der Kirche, und der Glaube nährt sich aus den Erfahrungen aller Gläubigen. Der Glaube selbst bildet ein Netz gegenseitiger Interdependenz, das zugleich „ein Netz gegenseitiger Verbundenheit, des Sich-Tragens und Getragenwerdens ist". 55 Der Glaube jedes Einzelnen soll im Rahmen des Wir-Glaubens der Kirche

\footnotetext{
${ }^{48}$ J. Ratzinger, AufChristus schauen, Freiburg-Basel-Wien 1989, S. 16 f.

${ }^{49}$ Ibidem, S. 9-14; S. 32 f.

${ }^{50}$ Ibidem, S. 13.

${ }^{51}$ Ibidem, S. $39 \mathrm{f}$.

52 Ibidem, S. 40.

${ }^{53}$ Ibidem, S. 33; siehe auch: J. Ratzinger, Schauen auf den Durchbohrten. Versuche zu einer spirituellen Christologie, Einsiedeln 1984, S. 70.

${ }^{54}$ J. Ratzinger, Auf Christus schauen, S. 40.

${ }^{55}$ Ibidem, S. 32.
} 
leben. Eine direkte, zu Jesus allein entwickelte Glaubensbeziehung würde für Ratzinger einen unvollständigen und zukunftslosen Glauben bedeuten. ${ }^{56}$ Gleichzeitig würde Gott selbst nicht in eine solche Beziehung, die eine private und ,individualistische Abkapselung “ ist, eintreten. ${ }^{57}$ Die Gotteserkenntnis als Dimension des Glaubens benötigt die Erfahrungen der Gemeinschaft, um damit eigene persönliche Erfahrungen durch die Erfahrungen der Gemeinschaft bestätigen zu können. ${ }^{58}$

\subsection{Die eucharistische Messe als Erscheinungsort der Communio zwischen Trinität} und Kirche

Das eucharistische Prinzip, welche die Kirche aufbaut, offenbart sich für Ratzinger nur durch seine liturgische Dimension. Die Kirche nennt sich Communio, weil ihr Konstitutionspunkt in der eucharistischen Versammlung liegt. Wer Eucharistie feiert, der wird durch Christus in die Communio mit dem dreieinigen Gott und mit den mitfeiernden Menschen hineingenommen und sichtbar als Teil dieser Communio identifiziert. ${ }^{59}$

\subsubsection{Die eucharistische Messe als Versammlungsort vom Volk Gottes}

Ratzinger ist sich bewusst, dass in der altkirchlichen Praxis eine der tiefsten Bedeutungen eucharistischer Messe in dem Ausdruck

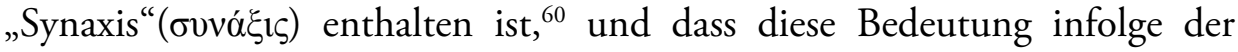
Konzilsdekrete des Zweiten Vaticanums neue Formen der Vergewisserung im Gottesvolk annahm. Die "Gemeinde“ als aktive Versammlung aller Gläubigen hat sich als eine der neuesten Wiederentdeckungen katholischer Reform gezeigt. Die Beziehung zu Gott braucht Ausdrucksformen, und die wichtigste von allen ist das gemeinsame festliche Hingehen zur Feier der Eucharistie. ${ }^{61}$ Daher betont Ratzinger die besonderen festlichen Formen des Zusammenkommens. Insbesondere werden von ihm das Pilgern und die Fronleichnamsprozession als deutlicher und für die Welt erkennbarer Versammlungsort des Gottesvolkes hervorgehoben. ${ }^{62}$ Das Sichversammeln

\footnotetext{
${ }^{56}$ Ibidem, S. 40.

${ }^{57}$ Ibidem, S. 33.

${ }^{58}$ Ibidem, S. 32.

${ }^{59}$ Miroslav Volf, Trinität und Gemeinschaft. Eine Ökumenische Ekklesiologie, Mainz 1996, S. $39 \mathrm{f}$.

${ }^{60} \mathrm{~J}$. Ratzinger, Das Fest des Glaubens. Versuche zur Theologie des Gottesdienstes, Einsiedeln 1981, S. 127.

${ }^{61}$ Ibidem, S. $116 \mathrm{f}$.

${ }^{62}$ Ibidem, S. 112-120, besonders S. 118.
} 
im Namen Jesu bringt selbst Kirche hervor, es ist ein unabhängiger und nicht institutionalisierter Akt, in dem die Kirche immer neu geboren wird. Aber zur Feier der eucharistischen Messe genügt diese von unten gebildete Struktur nicht. So wird eine im Namen Jesu versammelte Gruppe durch ihr inneres Einverständnis zusammengehalten, während ihre katholische Dimension abbröckelt. Ratzinger will das Herrenwort über die Versammlung von zwei oder drei ergänzen, weil sich in diesem Ausdruck nicht die ganze Realität der Kirche erfassen lässt. Als kirchenbildendes Prinzip genügt die Versammlung nicht. Um die Versammlung als Teil der wahren Kirche zu erweisen, fügt Ratzinger das bischöfliche Prinzip als notwendig hinzu.

In der Zusammenkunft aller Gläubigen in der Kirche und in der Eröffnung eines Dialogs zwischen dem Priester und den Gläubigen ist nur eine Dimension der eucharistischen Messe hervorgehoben. Die Isolierungsgefahr einer zur Eucharistiefeier versammelten Gemeinde soll durch die bewusste Anordnung zur sie öffnenden trinitarischen Dynamik überwunden werden. ${ }^{63}$ Die Gemeinde führt nicht ein Gespräch mit sich selbst, sondern befindet sich „im gemeinsamen Aufbruch zum wiederkommenden Herrn“. ${ }^{64}$

Die Christen versammeln sich nicht nur sichtbar in der einzelnen Gemeinde, sondern vielmehr unsichtbar um den Herrn in einer Reichweite, die das ganze Volk Gottes umfasst. Das soll nach Meinung Ratzingers den Grundlagen der Verkündigung Jesu entsprechen. Jesus Christus wollte für das Volk und nicht allein fürs Volk sterben, sondern dafür dass Er die zerstreuten Kinder Gottes zusammenführe ${ }^{65}$ (vgl. Jo 11, 52). Der Anstoß zur Versammlung kommt nicht nur durch den Willen der Menschen, sondern von der inneren Erweckung durch den Herrn, der alle sucht. ${ }^{66}$ Die Versammlung der Gemeinde zeigt die ständige Ausrichtung auf ihre Fülle, auf Katholizität. So wird die Katholizität keine von außen hinzugefügte Definition der Kirche, sondern ist der von Christus selbst stammende Impuls des vollen Lebens. ${ }^{67}$

Das Kreuz ist die Voraussetzung der Versammlung des Gottesvolkes. Das Kreuz als Mittel der Versammlung ist das Zeichen des Zueinanderkommens. In ihm findet das Volk Gottes die Vermittlung seines gemeinsamen Bezugspunktes und die Voraussetzung für die Zelebration: den gekreuzigten und auferstandenen Christus. Durch das Kreuz werden die beiden Aspekte

\footnotetext{
${ }^{63}$ Ibidem, S. 124.

${ }^{64}$ Ibidem.

${ }^{65}$ Ibidem, S. $127 \mathrm{f}$.

${ }^{66}$ Ibidem, S. 128.

${ }^{67}$ Ibidem, S. $128 \mathrm{f}$.
} 
eucharistischer Messe hervorgehoben. Die Wortliturgie und das Hochgebet der Kirche werden von Ratzinger als Hinwendungs- und Bekehrungswege zum Herrn gesehen. ${ }^{68}$

\subsubsection{Die eucharistische Messe als Lob des Reiches Gottes}

Das relationale Verständnis der Trinität ermöglicht es Ratzinger, das Gebet ins Zentrum seiner Kirchendefinition zu rücken. Er findet in der Heiligen Schrift umfassende Beweise für das dialogische Verhältnis zwischen Gott und Welt, „einerseits Offenbarung, Reden und Tun Gottes, und andererseits Antwort des Menschen, die das Wort Gottes aufnimmt und sich von Gott führen lässt“. ${ }^{69}$ Das Gebet wird dadurch zur tragenden Säule christlichen Glaubens. Die Kirche besteht aus dem ständigen Gebet als Dialog des Gottesvolkes mit dem dreieinigen Gott, und sie ist Frucht des Gebets genauso wie die Auswahl der Zwölf das Resultat einer ganzen Gebetsnacht Jesu gewesen ist ${ }^{70}$ (Lk 6,12 ff).

Ratzingers Ansicht über das Lob Gottes lässt sich konsequent in die katholische Überlieferung einordnen: Durch das Lob steigt das Volk Gottes auf zu Gott. Das Lob Gottes fasst für Ratzinger das Wissen, das Verstehen und das Tun in einer aufsteigenden Bewegung zu Gott zusammen. Das Lob trennt das Volk Gottes von seiner gewöhnlichen und zerstreuenden Beschäftigung und verbindet es mit dem Lobgesang der Engel. ${ }^{71}$ Ratzinger plädiert, insbesondere in seinen pastoralen Aufsätzen, für ein richtiges Verständnis des Begriffes „participatio actuosa“. Gegen die allgegenwärtige Meinung, dass „participatio actuosa“ unbedingt äußere Tätigkeiten - wie z. B. Reden, Singen, Predigen oder liturgische Assistenz - voraussetzt, betont Ratzinger aufgrund einer Randbemerkung über das Schweigen in der Liturgiekonstitution, die anderen Formen der „participatio actuosa“ am Lob der Trinität. ${ }^{72}$

Das Lob der Dreifaltigkeit kommt nicht nur durch Menschengesang zum Ausdruck, sondern auch durch die Kirchenmusik und durch die sakrale Kunst. Das trinitarische Lob trägt durch die Kirchenmusik, das Medium der Anbetung, zur Reinigung, zur Erhebung und zur Vergeistigung des Kosmos und der Menschen bei. ${ }^{73}$

\footnotetext{
${ }^{68}$ Ibidem, S. 125 f.
}

${ }^{69}$ Ibidem, S. 16.

${ }^{70} \mathrm{~J}$. Ratzinger, „Kirchliche Bewegungen und ihr theologischer Ort“, in: Internationale Katholische Zeitschrift 27 (1998), S. 431-448, hier 433.

${ }^{71}$ Idem, Das Fest, S. 102.

${ }^{72}$ Ibidem, S. 108 f; S. 116 f.

${ }^{73}$ Ibidem, S. 105. 


\subsubsection{Die eucharistische Messe als Ort der Verkündigung Christi}

Die eucharistische Messe des menschgewordenen Wortes ist notwendigerweise in einer spezifischen Art Wort-orientiert. ${ }^{74}$ In der Zuwendung zum Glauben geht es entscheidend um die Verkündigung der Wahrheit. Da man aber nur durch die Kirche zum Glauben kommen kann, ist der Zugang zur Wahrheit notwendigerweise eine ekklesiale Wahrheitsfindung, die für jeden Einzelnen durch das Erlernen der Sprach- und Lebensformen des Gottesvolkes erfolgt. ${ }^{75}$ Die christliche Wahrheit erschließt sich nur in der ganzen Kirche. ${ }^{76}$ Der Zugang des Gottesvolkes zur Wahrheit impliziert bei Ratzinger nicht, dass die Wahrheit durch die Kirche konstituiert wird. Vielmehr geht die Wahrheit der Kirche voraus; Christus als ständiger Ursprung der Kirche ist die Wahrheit. Deswegen kann man die Wahrheit nicht erfinden; man kann sie nur finden und zwar in der Kirche als Inhalt der Verkündigung und als Leib Christi. ${ }^{77}$

Die Auferstehung Christi bildet das zentrale Thema der Verkündigung der eucharistischen Messe. Die Verkündigung dieses Ereignisses bringt es immer mit sich, dass trinitarische Sprache verwendet wird. ${ }^{78}$ Diese Aussagen beweisen das Verharren bei der Lehre der Apostel, welche den Inhalt der christlichen Einheit darstellt. ${ }^{79}$

Jede christologische Aussage weist auf die Macht des Vaters und auf die Wirkung des Heiligen Geistes hin und verstärkt in der Gemeinde die Hoffnung auf die Parusie. In der kosmischen Orientierung der Zelebration der eucharistischen Messe nach Osten sieht Ratzinger mehrere miteinander verbundene theologische Auffassungen der Eucharistie: Die Auferstehungsdimension zeigt die Wirkung der Trinität im Volk Gottes und macht eine „parusiale“ und auf die Wiederkunft Christi zentrierte Interpretation der Eucharistie möglich. Diese Auslegung ist für Ratzinger die einzig berechtigte Hoffnungstheologie christlicher Kirche. ${ }^{80}$

Infolge biblischer Überlieferung glaubt Ratzinger, dass die

${ }^{74}$ Ibidem, S. 106.

75 J. Ratzinger, Theologische Prinzipienlehre. Bausteine zur Fundamentaltheologie, München 2005, S. 130.

${ }^{76}$ Ibidem, S. 32 f.

77 J. Ratzinger, Kirche, Ökumene und Politik. Neue Versuche zur Ekklesiologie, Einsiedeln 1987, S. 59-123; Vittorio Messori, Zur Lage des Glaubens. Ein Gespräch mit Kardinal Joseph Ratzinger, Freiburg 1985, S. 62.

${ }^{78}$ J. Ratzinger, Das Fest, S. 122.

${ }^{79}$ Idem, Schauen auf den Durchbohrten, S. 62.

${ }^{80}$ Idem, Das Fest, S. 122. 
Verkündigung Christi in der Kirche nicht nur im Wort zum Ausdruck kommt, sondern auch „im Zur-Sprache-Bringen der Musik der Schöpfung“. ${ }^{81}$ Die eucharistische Messe kann ihre wahre Dimension nur erhalten, wenn sie den ganzen Kosmos umfasst. Das Volk Gottes soll sich deswegen die kosmische Dimension der Eucharistie durch die Vergewisserung der eucharistischen Feier vergegenwärtigen. ${ }^{82}$

Die Verkündigung Christi vermittelt die christliche Wahrheit jedem Menschen und verwandelt ihn in eine anima ecclesiastica. Die Wahrheit soll in einer doppelten Transzendenz verankert werden: Die göttliche Wahrheit ist nur als die von der Gesamtkirche verkündete Wahrheit zu empfangen. Dabei ist die sakramental verankerte kirchliche Transzendenz wiederum Zeichen und Garantie der göttlichen Transzendenz.

\subsubsection{Die eucharistische Messe als Erweiterung des Leibes Christi}

Die Eucharistiefeier ist der Ort der Begegnung, wo die Menschen mit dem Tod und der Auferstehung Christi in unmittelbaren Kontakt kommen und wo die Christen zur lebendigen Kirche auferbaut werden. ${ }^{83}$ Ratzinger ist überzeugt, dass die reine Verkündigung einseitig und nicht ausreichend ist. Die bloße Begegnung mit der Schrift kann eine hilfreiche geschichtliche Rekonstruktion für die heutigen Menschen darstellen, aber in keinem Fall kann sie den wahrhaften Christus erfahrbar machen. Der wahrhafte Christus ist nur in seiner Präsenz erreichbar, welche bei Ratzinger durch die Kirche und in der Kirche zu finden ist. ${ }^{84}$

Das Beten der Kirche findet seine Mitte im Brotbrechen, und die Eucharistie wird von Ratzinger als das Herz des kirchlichen Lebens bezeichnet: „Kirche ist Eucharistie-Feiern; Eucharistie ist Kirche; beides steht nicht nebeneinander, sondern ist dasselbe. " ${ }^{85}$ Der Mensch, der dieses Brot aufnimmt, wird Christus gleich, er wird von ihm aufgenommen, wird eingeschmolzen in dieses Brot und wird Brot wie Christus selbst. Das ganze Leben jedes Christen wird umgestaltet. Die eucharistische Messe bricht das ganze Ich des Menschen auf und schafft ein neues Wir, in dem der Einzelne

${ }^{81}$ J. Ratzinger, „Zur theologischen Grundlegung der Kirchenmusik“, in: Franz Fleckenstein (Hg.), Gloria Deo-paxHominibus. Festschriftzum 100-jährigen Bestehen der Kirchenmusikschule Regensburg, Bonn 1974, S. 32 - 62, hier s. 34; J. Ratzinger, Das Fest, S. 101.

${ }^{82}$ J. Ratzinger, Das Fest, S. 122.

${ }^{83}$ Ibidem, S. 113.

${ }^{84}$ Ibidem, S. $26 \mathrm{f}$.

85 J. Ratzinger, Das neue Volk Gottes. Entwürfe zur Ekklesiologie, Düsseldorf 1969, S. 93 ff; siehe auch: J. Ratzinger, Zur Gemeinschaft gerufen. Kirche heute verstehen, Freiburg im Breisgau 1991, S. 70 f.; idem, Theologische Prinzipienlehre, S. 55. 
selbst ein Teil dieses neuen Brotes wird. Es kann geradezu gesagt werden, dass die Kirche ihrem Wesen nach eine durch Menschwerdung gestiftete Beziehung der Liebe ist, die ihrerseits eine neue Beziehung der Menschen untereinander begründet. Bei der sich wiederholenden Feier der Eucharistie wird die ekklesial vermittelte Vereinigung mit Christus, welche die Menschen zu Christen macht, indem sie die Menschen in die trinitarische und ekklesiale Communio einfügt, immer wieder von Neuem vollzogen: „Durch den sakramentalen Leib zieht Christus die Christen in sich hinein." Sie werden zum Totus Christus, d. h. Haupt und Leib, und tragen seine Existenz weiter durch die Zeiten. ${ }^{86}$ In dieser Betrachtungsweise nähern sich Ekklesiologie und Soteriologie, und dies macht die Überlegungen Ratzingers von der „Notwendigkeit der Eucharistie“, die nichts anderes als die Notwendigkeit der Kirche ist, verständlich: „Die Notwendigkeit der Eucharistie ist identisch mit der Notwendigkeit der Kirche und umgekehrt. ${ }^{\text {"87 }}$

Die durch den eucharistischen Leib Christi real vollzogene Vereinigung mit Christus zeigt, dass die Bezeichnung der Kirche als Leib Christi nicht nur auf das "geheimnisvolle Innere“ der Kirche hindeutet, sondern die sichtbare "Gemeinschaft derer, die miteinander Herrenmahl feiern“, bezeichnet. ${ }^{88}$ Wer Eucharistie feiert, der steht nicht nur durch Christus in der Gemeinschaft mit dem dreieinigen Gott und den mitfeiernden Menschen, sondern wird auch als solche identifiziert, meint Ratzinger. Wenn die Kirche von der eucharistischen Messe her als der Leib Christi verstanden wird, dann gewinnt ihr Leib-Christi-Sein „einen real fassbaren, geradezu juristisch umgrenzbaren Ausgangpunkt“. ${ }^{89}$ Die eucharistische Messe macht die Kirche zur Kirche: „Kirche ist ganz sich selbst nur im Sakrament, dort wo sie sich Ihm und Er sie ihr übereignet und sie immer neu erschafft - sie als der in die untersten Tiefen der Erde und des Menschseins Abgestiegene immer neu zur Höhe führt. "90

Jede örtliche Versammlung, in der die Eucharistie gefeiert wird, ist „unmittelbare und reale Verwirklichung von der Kirche selbst“, denn sie hat den Herrn ganz. ${ }^{11}$ Die Ekklesialität einer eucharistischen Gemeinschaft lässt sich deswegen auch nicht steigern. „Mehr als die eucharistische Gemeinschaft gibt es nicht. Die Einheit der Gesamtkirche ist in solcher Sicht pleromatische

\footnotetext{
${ }^{86}$ Idem, Das neue Volk, S. 83.

${ }^{87}$ Idem, Schauen auf den Durchbohrten, S. 79.

${ }^{88}$ Idem, Das neue Volk, S. 78.

${ }^{89}$ Ibidem, S. 84.

${ }^{90}$ J. Ratzinger, „Communio - ein Programm“, in: IkaZ 21(1992), S. 454-463, hier S. 461.

${ }^{91}$ J. Ratzinger, Kirche, Ökumene und Politik, S. 17.
} 
Steigerung, aber keine Ergänzung und keine Vermehrung der Ekklesialität. " Durch das Anteil-Haben der Christen an der eucharistischen Messe werden sie zum Leib Christi aufgebaut, und die Kirche wird in einer Einheit mit Christus identisch, meint Ratzinger. Durch diese Aussage ergibt sich eine weitere Frage: Wie aber ist diese Einheit zu verstehen? Bei der Antwort grenzt sich Ratzinger von dem in der Zwischenkriegszeit betriebenen Personalismus $\mathrm{ab}$, der Gott und die Menschen in den Rahmen der gemeinsamen Kategorie von Ich und Du denkt. ${ }^{93}$ Gegenüber Gott, der im Besitz des Seins durch Sich selbst ist, sind die Grundlagen menschlicher Identität in der Wirklichkeit, außer sich selbst. Die wahre Identität für die Christen liegt deshalb in der Entdeckung der zusammenführenden Rolle Christi in der Schöpfung, wo er als „der Erstgeborene aller Schöpfung“(Kol 1,15 ff.) auch unser Leben in Gott gründet und birgt. Ratzinger überträgt das biblische Modell, welches bei der Schöpfung von Adam und Eva vom Einswerden spricht („Sie werden zwei in einem Fleisch sein", Gen 2, 24; Eph 5, 30f), auf die Identität zwischen Christus und Kirche. Die Kirche wird zum Leib Christi durch die einsmachende Kraft der Liebe. Einerseits bewahrt die Liebe das Gegenüber von Ich und $\mathrm{Du}$, andererseits soll sie Ich und Du in einer unzerstörbaren Einheit einigen. ${ }^{94}$

Klar ist aber, dass wir in der Theologie Joseph Ratzinger von einer liturgischen Ekklesiologie sprechen können: Das versammelte Volk Gottes empfängt die Gabe des Geistes im Vollzug des eucharistischen Gebets.

\subsubsection{Die eucharistische Messe als sichtbare Verwirklichung der Communio zwischen} Trinität und Kirche

Das Alte Testament kennt keine Kommunion bzw. Communio zwischen Gott und Menschen. Das zwischen dem erwählten Volk und dem alttestamentarischen Gott existierende Verhältnis wird immer durch den Begriff „Bund“ (Berith) beschrieben. Für Ratzinger ist Kirche die im Neuen Testament durch die Person Jesus Christus offenbarte Kommunion (koinonia) zwischen der Trinität und den Menschen. Die Trinität öffnet durch die Inkarnation des Logos den Weg zum Unmöglichen: den wechselseitigen Dialog mit den Menschen. ${ }^{95}$ Vonseiten des Menschen bedeutet Christsein in

\footnotetext{
${ }^{92}$ J. Ratzinger, Theologische Prinzipienlehre, S. 308.

${ }^{93}$ Gemeint sind hier Buber, Ebner, Rosenzweig, Brunner, Steinbüchel u.a. Siehe: J. Ratzinger, Das Fest, S.27; Hansjürgen Verweyen, Joseph Ratzinger - Bededikt XVI. Die Entwicklung seines Denkens, Darmstadt 2007. S. 108-109.

${ }^{94}$ J. Ratzinger, Das Fest, S. 27.

${ }^{95}$ J. Ratzinger, Schauen auf den Durchbohrten, S. 76.
} 
Wirklichkeit nichts anderes, als eine gewisse Beteiligung am Geheimnis der Inkarnation. Diese Beteiligung wird in der Betrachtungsweise Ratzingers nur in der Eucharistie möglich. ${ }^{96}$

Die Erweiterung des Leibes Christi führt die Christen auf eine innere Bewegung hin zu Gott. Diese innere Richtung der eucharistischen Messe bleibt bei Ratzinger immer dieselbe, nämlich „von Christus im Heiligen Geist zum Vater hin“". ${ }^{97}$ Die äußere Gestaltung will Ratzinger in der trinitarischen Communio begründen. Genauso wie der Mond kein eigenes Licht ausstrahlt, sondern das Licht der Sonne weitergibt, soll die Kirche keine Selbstdarstellung menschlicher Komponenten billigen, sondern eine Widerspiegelung des Lichtes Christi $\operatorname{sein}^{98}$. Ratzinger ist der Meinung, dass die „unteilbare Einheit der Kirche“ besser in der Perichorese der drei göttlichen Personen als in dem Bild einer göttlichen Monarchie dargestellt wird. ${ }^{99}$ Nach Ratzinger soll diese göttliche Perichorese als Modell für die Beziehungen zwischen den Kirchen, Bischöfen und Gläubigen, d. h. zwischen verschiedenen gleichberechtigten Schichten in der Kirche, funktionieren. Aber die trinitarischen Relationen können nur die Spiritualität der Kirche und nicht ihre hierarchischen Strukturen prägen. Da jedes göttliche Ich in der Trinität „gänzlich vom Du her besteht“, können die Beziehungen zwischen den Personen überhaupt nicht strukturiert sein; denn jede Person ist ganz und gar transparent für die anderen. So gesehen sollen die Beziehungen zwischen den trinitarischen Personen ohne strukturelle Folgen bleiben. Im Sinne von Ratzingers trinitarischem Denken sollen die ekklesialen Strukturen über die eine Substanz Gottes zu denken geben. Die eine nach außen handelnde göttliche Substanz entspricht der einen Kirche, die zusammen mit Christus das eine Subjekt bildet und so handlungsfähig wird. Daraus ergibt sich eine monistische Struktur der Kirche: der eine in der Kirche als Subjekt handelnde Christus wird durch das eine sichtbare Haupt der Kirche repräsentiert - durch den Papst als Haupt der Universalkirche und den Bischof als das Haupt der Lokalkirche. So können als Strukturelemente der Kirche nur der eine Papst und der eine Bischof mit der Gotteslehre begründet werden, nicht dagegen das Kollegium der Bischöfe. Weil Ratzinger die Kirche vom Ganzen her denkt - von dem einen Subjekt der Kirche her -, müssen die Beziehungen zwischen dem Papst und den Bischöfen oder zwischen den Bischöfen und

${ }^{96}$ J. Ratzinger, Schauen auf den Durchbohrten, S. 74 f., S. 79.

${ }^{97}$ Idem, Das Fest, S. 121.

${ }^{98}$ Idem, „Warum ich noch in der Kirche bin“, in: Franz Heinrich, (Hg.), 2 Plädoyers, München 1971, S. 55-75, hier S. 65 ff.

${ }^{99}$ J. Ratzinger, Das neue Volk, S. 214. 
den Gemeindemitgliedern notwendig hierarchisch strukturiert sein. Wie in der Trinität Christus dem Wesen Gottes untergeordnet ist, so muss der Eine, der für die ganze Kirche zu bürgen hat - der Papst als Vicarus Christi - den Bischöfen übergeordnet sein, wie auch die Bischöfe den Priestern übergeordnet sein müssen. Da die Beziehungen als reine Relationen bestimmt sind, begegnet man im Idealfall einer linearen Reihe der selbstlosen Hierarchen: wie der Sohn im Bezug auf den Vater reine Relation ist, so sollen auch der Papst und die Bischöfe reine „vikarielle Macht“ besitzen. ${ }^{100}$ Die trinitarische Relationalität scheint die Macht der Hierarchen zu relativieren. Allerdings erscheint die hierarchische Macht in ihrem konkreten Vollzug immer auch als hierarchische Eigenmacht. ${ }^{101}$ Betrachtet man die ekklesialen Beziehungen in Analogie zu den trinitarischen reinen Relationen, dann ist dieser hierarchischen Eigenmacht nichts entgegenzusetzen als der gute Wille der Hierarchen. Über die Auffassung von Personen als reine Relationen kommt man nie auf die Rechte der Personen. Da die Person „nirgendwo nur auf sich selbst steht, “102 kann sie als reine Relation keine Rechte den anderen gegenüber haben. Wenn es zunächst so schien, als ob die reine Relationalität die hierarchische Struktur der Beziehungen relativiert, so gibt sie in Wirklichkeit den Hierarchen freie Hand zur Macht.

Die Communio der Kirche mit der Trinität bildet die Grundlage der Einheit der Kirche. Ratzinger behauptet, dass in dieser Communio durch die Ausstrahlung der österlichen Freude die einzig wahre Einheit besteht. In Konsequenz seiner ökumenischen Prinzipien betont Ratzinger, dass die Einheit weder in akademischer Polemik noch in wissenschaftlichen Theorien erreicht werden kann. Seiner Meinung nach sollen die Christen aller Konfessionen vielmehr einzig das gemeinsame Bekenntnis der österlichen Freude als Ausgangspunkt für die Begegnung miteinander und mit der Welt nehmen. ${ }^{103}$

\subsection{Die Wirkung eucharistischer Messe ins alltägliche Leben}

Ratzinger setzt das eucharistische Brot immer in eine wechselseitige Beziehung zum Brot des Alltags: das im Vater Unser erbetene tägliche Brot weist in nuce zur Eucharistie und zum Kirche-Werden hin, und das eucharistische Brot segnet das tägliche Brot. Dadurch öffnet sich die eucharistische Messe

\footnotetext{
${ }^{100}$ Idem, Kirche, Ökumene und Politik, S. 47.

${ }^{101}$ Ibidem.

102 J. Ratzinger, Einführung, S. 146.

${ }^{103}$ Idem, Das Fest, S. 115.
} 
für den Alltag und füllt unser ganzes irdisches Leben aus. Sie bricht aus dem sakralen Raum der Kirche heraus, und in der Überwindung aller persönlichen Grenzen umspannt sie Himmel und Erde, den ganzen Kosmos, Gegenwart und Eschaton. Ratzinger glaubt, dass durch die eucharistische Messe nicht nur die Gefahr der Umwandlung der Liturgie in eine private Feier abgewendet wird sondern auch dass durch sie Menschheit und Schöpfung, Himmel und Erde zusammengehalten werden können. ${ }^{104}$

Das Volk Gottes soll nach seiner Begegnung mit der Dreifaltigkeit nicht als verstreute Zweige christlich-menschlicher Unternehmungen, sondern als Kirche Gottes in die Realität dieser Welt zurückkehren. ${ }^{105}$ In den guten Taten, mit denen jeder Christ den aus dem Evangelium stammenden Auftrag erfüllt, handelt die heilige Kirche Gottes und nicht der einzelne Mensch. ${ }^{106}$ Der Auftrag der Kirche in der Welt geht in der Betrachtung Ratzingers über die Grenzen der Evangeliumsverkündigung hinaus. Seiner Meinung nach soll die Kirche zur Verbesserung, Humanisierung, Verwandlung und Vergeistigung dieser Welt beitragen. Es scheint, dass sich Ratzinger hier die Überzeugung Dostojewskis angeeignet hat. Dostojewski war überzeugt, dass „die Schönheit die Welt erretten wird“. Ratzinger glaubt das auch, er ist sicher, dass die Kirche in ihrer Mission für die Welt und in der Welt nur zwei „Apologien“ und Wahrheitszeugnisse hat: die Heiligen und die sakrale Kunst. ${ }^{107}$ In letzter soll die Kirche geeignete und würdige Antworten für die Herausforderungen ihrer Mission suchen. ${ }^{108}$

\subsection{Zusammenfassung}

Seine Sicht auf die Strukturen der Kirche und auf die Gestaltung der Eucharistie hat Ratzinger in Entsprechung zu seiner Trinitätsauffassung entwickelt. Seine eucharistische Ekklesiologie besagt, dass das neue Volk Gottes vom Leib Christi her zu verstehen ist. Die Kirche ist in der eucharistischen Messe sie selbst, weil sie darin ihre vollste und tiefste Identität findet. Die Einheit des Gottesvolkes ergibt sich primär aus dem Versöhnungscharakter der Eucharistie und aus der Verkündigung und wird im Bischofsamt dargestellt. Der Bischof verkörpert und vermittelt die Einheit der Kirche. Diese Einheit der verschiedenen Ortskirchen in gegenseitiger Kommunionsgemeinschaft

\footnotetext{
${ }^{104}$ Ibidem, S. 118.

${ }^{105}$ Idem, „Warum ich noch in der Kirche bin“, S. 67 f.

${ }^{106}$ Ibidem.

${ }^{107}$ Ibidem, S. 73 f; siehe auch: idem, Das Fest, S. 109.

${ }^{108}$ Idem, Das Fest, S. 109.
} 
benötigt allerdings bei Ratzinger einen sichtbaren Garant in der Person des Bischofs von Rom. ${ }^{109}$ Weil er die Kirche vom Ganzen her denkt, müssen die Beziehungen zwischen Papst und Bischöfen oder zwischen Bischöfen und Laien notwendig hierarchisch strukturiert sein. Das eucharistische Kirchenbild von Ratzinger kann man als kongruent mit der eucharistischen Ekklesiologie des Zweiten Vatikanischen Konzils bezeichnen.

\section{Würdigung}

Stăniloae denkt die Struktur der ekklesialen Beziehungen konsequent trinitarisch. Dieses ermöglicht ihm, seine von der Person des Vaters ausgehende, monarchische Trinitätstheologie. Wie in der Dreifaltigkeit, wo der Vater den Sohn und den Hl. Geist konstituiert, aber der Sohn und der Geist den Vater nur bedingen, so ist es auch in der Ekklesiologie: Christus konstituiert die Kirche, aber die Kirche bedingt ihn nur; und entsprechend konstituiert der Eucharistie zelebrierende Bischof die Kirche, aber die Kirche bedingt ihn nur. In der gesamten Beschreibung der Liturgie geht Stăniloae von einer unauföslichen und dynamischen Einheit des Gotteslobs, der Anamnese seiner heilenden Taten und der stetigen epikletischen Anrufung Gottes aus. Bei Stăniloae konstituiert die auf dem Altar einer konkreten Ortsgemeinde gefeierte Eucharistie die eine heilige katholische und apostolische Kirche. Dabei ist eine Einzelgemeinde ganz Kirche, aber natürlich nicht die ganze Kirche, denn viele Ortskirchen gehören zur Kirche. Wer also an einem konkreten Altar einer Ortskirche den Leib und das Blut Christi empfängt, wird mit dieser gesamten Ortsgemeinde Leib Christi. Deshalb ist die Teilhabe an der Eucharistiegemeinschaft auch wahrhafte Teilhabe an der Kirchengemeinschaft.

Neben dem Ortsbischof als einzig sichtbarem Zeichen der universalen Kirchengemeinschaft, benötigt Ratzinger immer eine zweite Rückkoppelung in der geschichtlich-juristischen Wirklichkeit der Kirche, nämlich im Amt des Papstes. Was in der Darstellung der Ekklesiologie als einer linearen Reihe der selbstlosen Hierarchen erfasst wird - weil die Beziehungen als reine Relationen bestimmt sind - lässt sich allerdings im konkreten Vollzug kaum umsetzen. Wie oben gezeigt, denkt und begründet Ratzinger die Beziehungen in der Kirche trinitarisch, aber die Kirchenstruktur bleibt monistisch. Das ist die Folge seiner westlichen Trinitätslehre: Die Dominanz des Einen in der Trinitätslehre hat wichtige ekklesiologische Entsprechungen. Das Eine ist sowohl für die Trinitätslehre wie auch für die Kirchenlehre strukturell

109 Thomas Weiler, Volk Gottes - Leib Christi, Mainz 1997, S. 68. 
entscheidend. Da nur eine Einheit die Ganzheit gewähren kann, muss der Papst dem Bischof übergeordnet sein, wie auch der Bischof der Gemeinde.

Die konkrete juristische Anbindung der Gemeinde an den Ortsbischof und an den Papst in Rom ermöglicht Ratzinger eine genauere Beschreibung des geschichtlichen und immer wiederkehrenden Aktes der Versammlung der Ortsgemeinden. Das Sich-Versammeln im Namen Jesu lässt seiner Meinung nach die Kirche entstehen. Dieser Aspekt wird von Stăniloae vollkommen

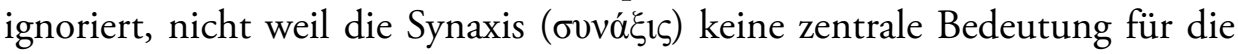
Hl. Liturgie hätte, sondern weil in seinem Liturgieverständnis die Christen schon von der Taufe her ständige und vollkommene Mitglieder der Kirche sind und weil die Liturgie die ganze sichtbare und unsichtbare Schöpfung umfasst.

Alle Sakramente werden von ihrer Zukunft her und auf ihre Zukunft hin von Ratzinger und Stăniloae auch als Mittel im Kampf gegen einen statischen Historizismus gesehen. Die Eucharistie wird bei den beiden Theologen weder nur als ein Objekt der Sakramentslehre noch als ein bloßes Gnadenmittel gesehen. Beide verstehen die Eucharistie vor allem als eine liturgische Handlung der Gemeinden. Die Eucharistie und die eucharistische Gemeinschaft sind identisch. Dementsprechend ist auch die Partizipation an der Verkündigung und an der Eucharistie nicht einfach Teilhabe an den heiligen Dingen, sondern an der vollkommenen Person Christi und dadurch an der vollkommenen Communio der Dreifaltigkeit. 